\title{
Implementação de políticas públicas: o Plano Brasil Sem Miséria no município de Curitiba
}

\section{Ingeborg Anni Rulf Cofré ${ }^{1}$ e Christian Luiz da Silva ${ }^{2}$}

\begin{abstract}
1 Mestre em Planejamento e Governança Pública pela UTFPR e graduada em Ciências Sociais pela UFPR. E-mail: ingecofre@yahoo.com.br

2 Doutor e Mestre em engenharia de produção e pós-doutor em administração pela USP. Graduado em Economia. Professor permanente do mestrado e doutorado do Programa de Pós-graduação de Tecnologia e Sociedade (PPGTE) e do Programa de Pósgraduação em Planejamento e Governança Pública (mestrado profissional) da Universidade Tecnológica Federal do Paraná. Professor do departamento de Gestão e Economia (DAGEE).E-mail: christianlsilva76@gmail.com
\end{abstract}

RESUMO: Este artigo busca analisar a discussão teórica em torno dos estudos de políticas públicas, especialmente àquela referente à fase de implementação do ciclo de políticas públicas a fim de compreender o processo de implementação das recentes políticas de combate à pobreza e extrema pobreza no Município de Curitiba. Para tanto, desenvolveu-se pesquisa descritiva e explicativa de base qualitativa, por meio de pesquisa bibliográfica, documentos oficiais, observação participante e entrevistas semi-estruturadas. Verificou-se que as políticas implementadas no Município dialogam com ambas as perspectivas top-down e bottom-up de implementação de políticas públicas, aproximando-se dos dois processos distintos de implementação, o processo de macro-implementação e de micro-implementação.

Palavras-chave: Políticas Públicas. Implementação. Plano Brasil Sem Miséria. Projeto Curitiba Sem Miséria.

Implementation of public policies: the Brazil Without Extreme Poverty Plan in Curitiba

\begin{abstract}
This article aims to analyze the theoretical discussion of the policy studies, especially the one regarding the implementation phase of the public policy cycle in order to understand the process of implementation of recent policies to combat poverty and extreme poverty in the city of Curitiba. Therefore, descriptive and explanatory research qualitative basis developed through literature, official documents, participant observation and semi-structured interviews. It was found that the policies implemented in the municipality dialogue with both top-down and bottom-up perspectives of implementation of public policies, approaching the two different implementation processes, the process of implementing macro-and microimplementation.
\end{abstract}

Keywords: Public Policy. Implementation. Brazil Without Extreme Poverty Plan. Curitiba Project Without Extreme Poverty.

\section{INTRODUÇÃO}

A promulgação da Constituição Federal de 1988 representou um marco para a sociedade brasileira, transformando a dinâmica democrática, as relações econômicas e sociais do país, além de reconhecer diversos direitos sociais e estabelecer alguns objeti- vos da República, como o de construir uma sociedade livre, justa e solidária, e de erradicar a pobreza e reduzir as desigualdades sociais e regionais no país (BRASIL, 1988). Dessa forma, é a Carta Magna que têm orientado as escolhas das políticas sociais brasileiras nos últimos anos, especialmente as políticas de combate à pobreza que passa- 
ram a ter o direito social como fundamento das ações públicas (DRAIBE, 1998).

Tal reordenamento das políticas públicas brasileiras tem refletido nos estudos sobre políticas públicas, que têm apresentado importante crescimento no país nos últimos anos. No entanto, no que se refere às pesquisas sobre a etapa de implementação do ciclo da política pública, pode-se dizer que estas são ainda bastante incipientes (FARIA, 2012). É com o intuito de analisar algumas concepções sobre os estudos de políticas públicas, especialmente ao que concerne ao processo de implementação, que este artigo se insere. Assim, este artigo procura analisar a discussão teórica em torno da fase de implementação de políticas públicas do 'policy cycle' a fim de compreender o processo de implementação das recentes políticas de combate à pobreza e extrema pobreza no Município de Curitiba.

Para tanto, realizou-se uma pesquisa descritiva e explicativa (GIL, 2007) de base qualitativa (MINAYO; SANCHES, 1993), por meio de pesquisa bibliográfica em artigos e livros científicos, documentos oficiais relacionados ao tema, observação participante e entrevistas semiestruturadas. Assim, foram realizadas 6 entrevistas com seis profissionais da Fundação de Ação Social de Curitiba (FAS), responsável pelas ações de combate à pobreza no Município, sendo uma entrevista com profissional da Superintendência de Planejamento, da Diretoria de Proteção Social Básica, da Diretoria de Informações e Gestão de Benefícios, e três profissionais de uma das dez Regionais Administrativas de Curitiba, sendo destes dois profissionais do CRAS. A observação participante esteve compreendida por três visitas a um Território Priorizado, sendo que uma visita envolveu uma ação pública realizada no local. Dessa forma, tanto as observações realizadas no território quanto às visitas ao CRAS para a realização das entrevistas, possibilitaram compreender o universo - que inclui o espaço físico, os diversos atores e suas relações - em que as políticas públicas são implementadas.

$\mathrm{O}$ artigo encontra-se organizado em quatro seções, incluída esta introdução. Na seção seguinte é realizada uma revisão teórica sobre políticas públicas e implementação de políticas; para na terceira seção analisar o processo de implementação do Plano Brasil Sem Miséria (BSM) no Município de Curitiba. Já na quarta e última seção, são tecidas as considerações finais.

\section{POLÍTICAS PÚBLICAS E IMPLEMENTAÇÃO}

Quando se trata de conceituar política pública, Souza (2006) ressalta que não existe uma única, nem melhor, definição sobre o que seja política pública. A autora cita a definição de Lynn (1980 apud SOUZA, 2006, p.24) de que políticas públicas são um conjunto de ações do governo que irão produzir efeitos específicos. Já para Dye (2011), política pública é o que o governo escolhe fazer ou não fazer. Nesse sentido, Kraft e Furlong (2010) afirmam que política pública é uma ação ou omissão do governo - associada a metas, recursos e regulamentos com vistas a lidar com problemas públicos.

Com efeito, as definições de política pública chamam a atenção para a ação dos governos que ocorre não sem o embate em torno de interesses, ideias e preferências; englobando indivíduos, instituições, interações e ideologias cada qual com influências variadas nos resultados da ação (SOUZA, 2006). Dessa forma, Souza (2006) define política pública como "o campo do conhe- 
cimento que busca, ao mesmo tempo, 'colocar o governo em ação' e/ou analisar essa ação (variável independente) e, quando necessário, propor mudanças no rumo ou curso dessas ações (variável dependente)" (SOUZA, 2006, p.26).

Nesse sentido, tal campo de conhecimento deve levar em conta, segundo Frey (2000), as três dimensões da política, a saber: a 'polity' que se refere à dimensão institucional abrangendo a ordem do sistema político, incluindo o sistema jurídico e a estrutura institucional do sistema políticoadministrativo; a 'politics' que diz respeito à dimensão processual da política, reconhecendo seu caráter conflituoso; e a 'policy' referente aos conteúdos concretos da política, ou seja, dos programas políticos, os problemas técnicos e o conteúdo material das decisões políticas. Tais dimensões, como lembra o autor, podem ser separadas para uma análise mais específica, mas não se deve ignorar que na realidade política são entrelaçadas e se influenciam mutuamente. Dessa forma, a análise de políticas públicas ou a abordagem da 'policy analysis', de acordo com Frey (2000), visa compreender a inter-relação entre as instituições políticas, o processo político e os conteúdos de política.

Nesse sentido, um modelo de análise de políticas públicas seria o modelo do ciclo da política pública ou 'policy cycle' (FREY, 2000; SOUZA, 2006). Este ciclo seria um processo dinâmico e deliberativo formado por várias etapas que se desenvolvem ao longo do tempo. De acordo com Frey (2000), a análise das diferentes fases permite refletir sobre as relações de poder, as redes políticas e sociais e as práticas político-administrativas do Estado. Dessa forma, tal abordagem analítica, estaria dividida de um modo geral em quatro fases centrais: a definição da agenda ou 'agenda setting'; a identificação de alternativas e a elaboração de programas e de decisão; a implementação de políticas; e, a avaliação de políticas e correção de ação (FREY, 2000; SOUZA, 2006; LOTTA, 2010).

As etapas do modelo do ciclo da política se apresentam apenas como uma ferramenta operacional para a análise de políticas. Na realidade, do dia a dia das políticas públicas, as fases geralmente não ocorrem de maneira sequencial, mas se cruzam, se confundem, e se relacionam (DYE, 2011; FREY, 2000; LOTTA, 2010). É nesse sentido, que Frey (2000) chama a atenção para o fato de que as diversas fases do 'policy cycle' se entrelaçam e se sobrepõem na prática, sendo o modelo um "tipo puro" que subsidia a 'policy analysis' para o reconhecimento de "pistas às possíveis causas dos déficits do processo de resolução de problema" (FREY, 2000, p.229).

Tais "pistas" foram o que mais motivou pesquisas sobre implementação de políticas públicas, segundo Barrett (2004). A autora afirma que o fim da década de 1960 e início da de 1970 pode ser caracterizado como o período em que houve grande preocupação a respeito da efetividade das políticas públicas e governança; a fim de melhorar os processos de tomada de decisão e a coordenação da política, assim como a gestão e a prestação de serviços públicos. Hill e Hupe (2002) também apontam para a década de 1970 como o início dos estudos sobre implementação, momento em que foram publicados trabalhos como o de Hargrove, de 1975 , sobre o "elo perdido" nos estudos sobre "policy process" e o livro "Implementation" de Pressman e Wildavsky, publicado em 1973 (HILL; HUPE, 2002, p.18). Esse pe- 
ríodo, portanto, esteve marcado pelos estudos orientados em compreender o porquê do sucesso e, principalmente, do fracasso de algumas políticas públicas.

Segundo Barrett (2004), a maioria dos estudos iniciais sobre políticas públicas tinham como foco o processo de formulação da política, e assumiam a implementação como um processo essencialmente administrativo e hierárquico. A política era entendida como sendo formulada pelo 'topo' e uma vez legitimada, a sua implementação era uma consequência do sistema administrativo cujas instruções operacionais seguiam um movimento hierárquico do topo para a base da pirâmide. Contudo, quando a questão da efetividade das políticas públicas começou a chamar a atenção, alguns estudos começaram a apontar para possíveis "falhas na implementação", o que incluía desde falta de objetivos claros à problemas de comunicação e interesses diferentes entre atores e órgãos (BARRETT, 2004).

Dessa forma, por meio de tais questionamentos, Barrett (2004) afirma que se passou a sugerir que a implementação fosse vista como sendo parte integrante e permanente do processo político, ao invés de uma consequência administrativa; o que implica reconhecê-la como uma ação política que envolve negociação e barganha entre aqueles que pretendem colocar a política em ação e aqueles sobre os quais a ação depende. Assim, a autora ressalta que a nova perspectiva passa a dar mais ênfase para as estruturas de poder e interesse e as relações entre os atores participantes e as agências, e a natureza das relações que tomam conta do processo, como fatores chave que moldam a implementação e os resultados das políticas.
Desse modo, o debate sobre os estudos de implementação de políticas públicas esteve marcado, principalmente, pela emergência de duas perspectivas: a top-down e a bottom-up (BARRETT, 2004; HILL; HUPE, 2002; LIMA; D'ASCENZI, 2013; LOTTA, 2010). Segundo Barrett (2004), o modelo top-down caracteriza-se pela separação entre política e administração, em que se enfatiza a coordenação e o controle através de autoridade e hierarquia. A preocupação era colocar a política pública em ação, e para tanto se entendia que a mesma deveria ser formulada no 'topo' e executada por agentes de acordo com os objetivos definidos previamente. Assim, como destacado por Lima e D'Ascenzi (2013), o processo de formulação da política pública seria caracterizado pela lógica da atividade política, enquanto que a implementação estaria no âmbito da administração pública, sendo esta consequência daquela. É nesse sentido que o foco de análise desta abordagem é o processo de formulação da política pública e as normas que as estruturam, pois "se a implementação é uma consequência, a explicação para sua trajetória está no processo que lhe deu origem" (LIMA; D'ASCENZI, 2013, p.103). O papel dos estudos de implementação, segundo esta perspectiva, como ressaltado por Barrett (2004), é identificar as causas dos problemas na implementação e sugerir formas de obter acordo entre as ações implementadas e os objetivos da política, como a elaboração de estratégias para melhorar a comunicação das intenções ou a coordenação dos "elos da cadeia" de implementação, entre outras.

Nesse sentido, Hill e Hupe (2002) salientam que para Pressman e Wildavsky a implementação é definida como a relação da política com o que consta nos documentos 
oficiais. Grande parte da análise feita no livro "Implementation" estaria preocupada com a questão de em que medida o sucesso da implementação dependeria das ligações entre diferentes organizações e departamentos do nível local, ou seja, a ação dependeria do número de elos da "cadeia de implementação"; no sentido de encontrar explicações para as dificuldades de se atingir os objetivos definidos na formulação da política pública. Com efeito, Lima e D’Ascenzi (2013) apontam algumas características da abordagem top-down ao afirmar que:

Limitar, regular e controlar a discricionariedade dos implementadores são questões centrais. Regras claras, compreensíveis e específicas visam permitir a difusão do plano e minimizar a discrição, considerada uma distorção da autoridade governamental. Às falhas de comunicação comumente é atribuído o fracasso do processo de implementação, sempre julgado como base no grau de alcance dos objetivos previamente definidos. (LIMA; D'ASCENZI, 2013, p.103).

Desse modo, a política que "consta nos documentos oficiais" é o principal objetivo do processo de implementação segundo esta perspectiva, e para tanto são necessários controle e hierarquia sobre a prática administrativa a fim de atingir tal objetivo. Como lembram Lima e D’Ascenzi (2013), alguns estudiosos chegaram a apontar variáveis independentes para que auxiliassem o estudo sobre implementação com intuito de evitar possíveis "falhas" nesse processo. É o caso de Sabatier e Mazmanian (1980) que desenvolvem um quadro de análise para a "identification of variables, particularly with respect to the manner in which statutory characteristics affect subsequent events" (SABATIER; MAZMANIAN, 1980, p. 538).

Para estes autores americanos o papel crucial da análise de implementação é identificar os fatores que afetam o alcance dos objetivos da política, os quais "falhariam" sobre três aspectos: "1) tractability of the problem; 2) non-statutory variables affecting implementation; 3 ) ability of statute to structure implementation" (SABATIER; MAZMANIAN, 1980, p. 542); sendo este último fator um dos mais importantes para se obter o controle sobre a implementação. Dessa forma, após uma análise do processo haveria recomendações ao "topo" a fim de controlar o processo de implementação na busca de atingir os objetivos previamente formulados pela política, uma vez que, como observado por Lima e D'Ascenzi (2013, p.103):

Os autores [da perspectiva top-down] estão preocupados com os elementos que podem comprometer o êxito da implementação. O parâmetro de sucesso são os objetivos definidos no plano. As variáveis referem-se à arena de formulação e focam elementos considerados estruturantes da implementação.

O foco no 'topo', no processo de formulação como definidor de todo o processo de implementação, no entanto, começa a ser questionado. É com base na crítica de que os formuladores da política poderiam controlar os implementadores a executar os objetivos formulados previamente, que surgem novos estudos realizados através da perspectiva que ficou conhecida como bottom-up. De acordo com Barrett (2004), esta abordagem entende a implementação co- 
mo parte de um continuum do processo de policy-making em que a política se modifica ao longo do processo de tradução das intenções em ação. Esta perspectiva, segundo a autora, está associada a uma visão da micropolítica do comportamento intra e interorganizacional, e inclui diversos modelos em que ora se enfatiza a construção de consensos, ora os conflitos e o exercício de poder na relação entre política e ação. Lima e D’Ascenzi (2013) igualmente observam que esta perspectiva chama a atenção para os elementos dos contextos de ação nos quais a política será implementada, como as condições dos espaços locais e as burocracias implementadoras.

Portanto, o foco das análises de implementação através da abordagem bottom-up está centrada nos atores dos níveis organizacionais responsáveis pela implementação e suas relações. Assim, compreende-se o processo de implementação não apenas como uma prática administrativa e consequência da formulação da política no 'topo', mas que tal processo é composto por diversos atores em interação e negociação que afetam os resultados da política.

Lispky (2010), com sua obra Street-Level Bureaucracy: dilemmas of indivudual in public services, publicada originalmente em 1980, é considerado um dos maiores representantes da perspectiva bottom-up de análise do processo de implementação de políticas públicas, sendo chamado por Hill e Hupe (2002) de o "founding father" desta perspectiva. Em seu trabalho, faz uma análise do comportamento daqueles servidores públicos que ele denominou "street-level bureaucrats" ou burocratas do nível de rua. No prefácio da edição de comemoração do $30^{\circ}$ aniversário da obra, Lipsky (2010, p.xi) afirma que:
This book is in part a search for the place of the individual in those public services I call street-level bureaucracies. These are the schools, police and welfare departments, lower courts, legal services offices, and other agencies whose workers interact with and have wide discretion over the dispensation of benefits or the allocation of public sanctions.

Dessa forma, Lipsky (2010) chama a atenção para o fato de que o exercício da discricionariedade é uma dimensão crítica do trabalho de professores, assistentes sociais, policiais e outros servidores públicos que trabalham e interagem diretamente com os cidadãos beneficiários do serviço público. O autor observa ainda que a performance destes servidores muitas vezes não está de acordo com os padrões dos formuladores da política, seja porque os burocratas do nível de rua apresentam falta de tempo, informação ou outro recurso necessário para responder adequadamente. Assim, os burocratas do nível de rua resolvem suas dificuldades de trabalho desenvolvendo práticas de rotina e influenciando fortemente o resultado de seus esforços. Tais dificuldades se devem ao fato de os burocratas do nível de rua, de um lado, sofrerem pressões por demandas de serviços, para aumentarem a efetividade e a responsividade, e de outro por sofrerem pressões dos cidadãos para aumentarem a eficiência e a eficácia. É nesse sentido que Lipsky (2010) afirma que tais práticas e rotinas adotadas para responder algumas incertezas e pressões do trabalho acabam se tornando efetivamente na política pública. Salienta que:

[...] I maintain that public policy is not best understood as made in legislatures 
or top-floor suites of high-ranking administrators. These decision-making arenas are important, of course, but they do not represent the complete picture. To the mix of places where policies are made, one must add the crowded offices and daily encounters of street-level workers. Further, I point out that policy conflict is not only expressed as the contention of interest groups, as we have come to expect. It is also located in the struggles between individual workers and citizens who challenge or submit to clientprocessing (LIPSKY, 2010, p.xiii).

A relação entre o servidor público e o cidadão beneficiário, portanto, segundo Lipsky (2010), também molda a política pública. Isso se deve ao fato de que, para o autor, os burocratas de nível de rua que prestam serviço público que interagem com cidadãos, em determinado momento no exercício de seu trabalho, se não o podem realizar de acordo com as condições ideais de prática por causa de limitações, acabam por utilizar certa discricionariedade ao exercer autoridade. No entanto, não é todo burocrata de nível de rua que irá agir em desconformidade com os objetivos da organização, assim como todo trabalhador da linha de frente não adota mecanismos diferenciados o tempo todo. A questão levantada pelo autor é que mesmo que as dimensões das políticas oficiais moldem alguns padrões de decisão e normas administrativas, os burocratas do nível de rua ainda conseguem ter autonomia para decidir como aplicá-las e inseri-las nas práticas de implementação.

Dessa forma, o "quadro completo" do processo de implementação de políticas públicas inclui não somente as negociações e tomadas de decisões no topo, mas igual- mente as relações entre os atores na ponta, como os burocratas do nível de rua e os cidadãos. É a partir desse contexto complexo que se busca compreender o processo de implementação do Plano Brasil Sem Miséria (BSM) - a priori elaborado no "topo" no Município de Curitiba - implementado no "nível de rua".

\section{IMPLEMENTANDO O PLANO BRASIL SEM MISÉRIA (BSM) NO MUNICÍPIO DE CURITI- BA}

O Plano Brasil Sem Miséria (BSM) foi lançado pelo governo federal em 2011, como um conjunto de ações articuladas, em nível intersetorial e intergovernamental, com o objetivo de enfrentamento da pobreza e extrema pobreza no país (BRASIL, 2011). A nível local, no município de Curitiba, ele se traduz no Projeto Curitiba Sem Miséria (CSM), integrante do Programa Curitiba Mais Humana - ambos sob responsabilidade da Fundação de Ação Social de Curitiba (FAS) - do eixo de Desenvolvimento Social do Plano Plurianual do Município para os anos de 2014-2017. Assim, como o Plano federal, o CSM é formado por três eixos: i) garantia de renda; ii) acesso a serviços e iii) inclusão produtiva (CURITIBA, 2015a, 2015b). Tal articulação de políticas variadas nos três eixos reflete a concepção de que a situação de pobreza, e de extrema pobreza, não se restringe à insuficiência de renda, sendo necessária uma ação estatal integrada e intersetorial para o atendimento das necessidades dos indivíduos e famílias nessa situação (FONSECA et al, 2013).

Primeiramente, tem-se que o públicoalvo do CSM é compreendido pelas famílias e indivíduos com renda familiar per capita 
de até $R \$ 77,00^{1}$ e famílias e indivíduos que residam em Território Priorizado independentemente da renda familiar per capita, mediante avaliação técnica ${ }^{2}$. Os Territórios Priorizados são áreas concentradoras de vulnerabilidades, e ou, riscos sociais que demandam uma ação mais integrada e intersetorial (CURITIBA, 2015a, 2015b). Tal projeto de atuação intersetorial em Territórios Priorizados em Curitiba surgiu de uma experiência local ${ }^{3}$ em que houve uma demanda de diversas ações de variados setores, o que exigiu ampliar o olhar para os problemas complexos e o planejamento de uma atuação mais integrada e intersetori$\mathrm{al}^{4}$. A ação nos territórios tem suporte de uma organização local de atores municipais, os Colegiados Regionais de Gestão Integrada. Estes são instâncias de articulação e pactuação que tem a função de coordenar e implementar o Programa Curitiba Mais Humana em âmbito regional ${ }^{5}$; e dentro do

\footnotetext{
${ }^{1}$ Tal valor corresponde ao ano de 2015.

2 Tal critério de possibilidade de inclusão de beneficiários para além da renda é uma característica do Projeto municipal, diferenciando-se do Plano federal que seleciona as famílias e indivíduos apenas pelo corte de renda.

3 Tal experiência refere-se ao ano de 2003 em que houve a constatação de muitos casos de Defesa Civil, em que devido a enchentes e alagamentos, muitas famílias residentes em áreas precárias acabaram perdendo suas casas. A partir desta situação começaram a ser pensadas propostas de trabalho conjunto sobre determinados territórios, num sentido de ir além do atendimento individual de famílias, e de construir um olhar para atuar no conjunto do território e suas necessidades coletivas. (Entrevistado 3).

${ }^{4}$ Tal opção de trabalhar localmente com Territórios demonstra o diálogo estabelecido com a Política Nacional de Assistência Social (PNAS) (BRASIL, 2004), que traz a possibilidade de atuação socioassistencial por meio da perspectiva territorial.

${ }^{5}$ Curitiba é formada por dez Regionais Administrativas, que são uma espécie de subprefeitura encarregadas dos bairros. Cada Regional conta igual-
}

Programa Curitiba Mais Humana encontrase o Projeto Curitiba Sem Miséria (ENTREVISTADO 3).

O processo de implementação do CSM, compreende desde atores envolvidos com espaços de negociação e tomada de decisão à atores que estão diretamente em contato com os beneficiários. Nesse sentido, as ações implementadas dialogam ora com a perspectiva top-dowm de implementação, ora com a perspectiva bottom-up.

Tem-se, primeiramente, que a porta de entrada do beneficiário ao Projeto são os equipamentos do Sistema Único de Assistência Social (SUAS), os Centros de Referência Especializado da Assistência Social (CREAS) e, especialmente, os Centros de Referência da Assistência Social (CRAS). É, principalmente, por meio do atendimento realizado pelos burocratas do nível de rua nos CRAS que os indivíduos e famílias tem acesso ao Cadastro Único Para Programas Sociais do Governo Federal (Cadúnico). Estar inscrito no Cadastro Único é condição obrigatória para ter acesso ao CSM e aos serviços e benefícios vinculados aos três eixos de atuação (ENTREVISTADO 2).

Com efeito, as famílias são cadastradas pelos burocratas do nível de rua nos equipamentos do SUAS, cujos profissionais por sua vez são igualmente encarregados da atualização dos cadastros que são enviados à Diretoria de Informação e Gestão de Benefícios (DIGB). É esta Diretoria da FAS a responsável pela gestão local do Cadastro Único e do Programa Bolsa Família (PBF) no município, sendo que a competência de coordenação geral do Sistema do Cadastro Único e do PBF cabe ao governo federal por

mente com uma Rua da Cidadania, local onde são ofertados essencialmente serviços municipais, mas igualmente estaduais e federais. 
meio da Secretaria Nacional de Renda de Cidadania (SENARC) do Ministério de Desenvolvimento Social e Combate à Fome $(\mathrm{MDS})^{6}$. Assim, esta etapa do processo de implementação do Cadúnico e do PBF envolve tanto aspectos de relações com o "topo" em que são estabelecidas relações mais hierárquicas entre os atores - como a DIGB e a SENARC - quanto relações do nível de rua - em que sejam os servidores dos CRAS, que realizam as entrevistas cadastrais, ou da mesma DIGB que atuam na atualização e verificação cadastral - estabelecem relações junto à população beneficiária (ENTREVISTADO 2).

Dessa forma, a implementação do eixo de garantia de renda do CSM compreende a implementação dos benefícios do Programa Bolsa Família (PBF), do Benefício de Prestação Continuada (BPC), do benefício Renda Família Paranaense ${ }^{7}$, e do benefício municipal de renda vinculado à segurança alimentar, o Cartão do Armazém da Família ${ }^{8}$. Como já assinalado, a gestão do PBF é de responsabilidade a nível local da DIGB, que por sua vez, juntamente à Secretaria Municipal de Abastecimento (SMAB) administra o

\footnotetext{
${ }^{6}$ Tais dados referem-se ao ano de 2015, atualmente o MDS corresponde ao Ministério do Desenvolvimento Social e Agrário.

${ }^{7}$ O Programa estadual de Renda Família Paranaense, que corresponde a um complemento de renda aos já beneficiários do PBF, com renda familiar per capita superior a $\mathrm{R} \$ 77,00$ e inferior a $\mathrm{R} \$ \mathbf{8 7 , 0 0}$, elevando a linha da extrema pobreza para $\mathrm{R} \$$ 87,00 per capita. Este benefício estadual utiliza os mesmos critérios de condicionalidades do Programa Bolsa Família, além dos mesmos instrumentos de gestão, como o Cadastro Único.

${ }^{8}$ Este benefício corresponde a um crédito mensal, atualmente no valor de $\mathrm{R} \$ 50,00$, não acumulável, para o acesso a gêneros alimentícios e materiais de higiene e limpeza a um preço $30 \%$ inferior ao preço praticado no mercado nos espaços denominados Armazéns da Família.
}

subsídio alimentar municipal. Já ao que se refere ao benefício estadual, a estrutura do PBF, que inclui o Cadastro e a Caixa, acabam por gerir o programa uma vez que este funciona apenas como um complemento à renda dos já beneficiários do PBF. Tal estrutura do Cadastro Único e do PBF atendem as diretrizes nacionais de gestão, em que são estabelecidas as competências específicas para cada ente da federação, sendo então o governo local o responsável pela operacionalização dos mesmos.

No que concerne o eixo do acesso a serviços, a implementação das ações ocorre principalmente por meio dos equipamentos do CRAS. São os burocratas do nível de rua destes equipamentos que ao estabelecerem contato com os beneficiários oferecem, em um primeiro momento, os benefícios e serviços vinculados ao Cadastro Único ${ }^{9}$, para em seguida oferecer os serviços socioassistenciais ofertados pelo SUAS, como o Serviço de Proteção e Atendimento Integral à Família (PAIF) e o Serviço de Convivência e Fortalecimento de Vínculos $(\mathrm{SCFV})^{10}$. Neste momento, o burocrata do nível de rua exerce a sua discricionariedade ao fazer uma avaliação sobre a importância que a inclusão do beneficiário ao projeto trará à família tida como elegível. Ou seja, o servidor

\footnotetext{
${ }^{9}$ São 11 os benefícios vinculados ao Cadastro e ofertados na Cartilha elaborada pela DIGB: i) PBF; ii) BPC; iii) Carteira do Idoso; iv) Programa Nacional de Acesso ao Ensino Técnico e Emprego (Pronatec); v) Programa de Erradicação ao Trabalho Infantil (PETI); vi) Programas Habitacionais como o Minha Casa Minha Vida; vii) Tarifa Social de Energia Elétrica; viii) Telefone Popular; ix) Carta Social; x) Isenção da Taxa de Concursos Públicos e Vestibulares Federais; xi) Benefício Previdenciário de Donas(os) de Casa.

${ }^{10}$ Para maiores informações sobre os serviços socioassistenciais ofertados pelo SUAS ver BRASIL (2009).
} 
público analisa a família como um todo e avalia a sua possibilidade de aderência ao projeto municipal de enfrentamento à pobreza, no qual a família beneficiária teria acesso a benefícios de garantia de renda, benefício de subsídio alimentar, acesso a diversos benefícios e serviços socioassistenciais com prioridade (ENTREVISTADO 6, 4 e 5).

Os burocratas do nível de rua que se encontram nos CRAS estabelecem, ainda, um pacto junto à família, em que se busca conhecer as potencialidades e vulnerabilidades de todos os membros da família a fim de constituir um Plano de Acompanhamento Familiar em que o burocrata propõe intervenções a serem feitas juntamente à família (ENTREVISTADO 6, 4 e 5). Observa-se, portanto, as características de discricionariedade e autonomia dos burocratas do nível de rua, apontados por Lipsky (2010), na atuação destes atores locais junto à população beneficiária.

Tal atendimento mais próximo dos beneficiários do CSM é igualmente observável junto às ações do eixo de inclusão produtiva. O Projeto municipal de enfrentamento à pobreza e extrema pobreza tem como principais ações deste eixo, programas que dialogam com o conceito de "mundo do trabaIho" trazido pelo Programa Nacional de Promoção do Acesso ao Mundo do Trabalho (Acessuas Trabalho) (BRASIL, 2012). Este conceito é priorizado ao de "mercado de trabalho" por ser um termo mais amplo e adequado às ações implementadas, que buscam ir além da qualificação profissional e intermediação de mão de obra para fomentar uma preparação e formação cidadã em torno do mundo do trabalho.

Nesse sentido, os principais programas implementados no município que fazem parte do eixo de inclusão produtiva são o Programa Mobiliza e o Programa Fas Aprendiz, em que ambos os programas municipais são desenvolvidos pela FAS. O Programa Mobiliza é implementado por profissionais da FAS por meio de metodologia própria no qual se prioriza o trabalho com grupos fomentando a compreensão de cada um como sujeito coletivo, num processo de aprendizagem tanto do beneficiário quanto do burocrata do nível de rua. As ações implementadas incluem ainda articulações com diversas entidades que possibilitam ampliar o olhar do beneficiário ao mundo do trabalho, como visitas a museus, universidades, empresas (ENTREVISTADO 1).

Dessa forma, o conjunto das ações implementadas dentro do Projeto Curitiba Sem Miséria (CSM) é bastante diverso no que se refere às perspectivas de implementação, como a top-down e bottom-up, compreendendo ações com um perfil mais hierárquico e de respeito às normas e diretrizes nacionais à ações mais autônomas e que permitem certa discricionariedade por parte de seus atores públicos.

\section{CONSIDERAÇÕES FINAIS}

O processo de implementação do Plano Brasil Sem Miséria (BSM) no Município de Curitiba, como visto, se traduz no Projeto Curitiba Sem Miséria (CSM). Este projeto local adota as mesmas diretrizes do plano federal, porém incorpora novos elementos a fim de melhor atender as demandas locais e devido aos aspectos institucionais locais. Nesse sentido, o CSM ao organizar-se nos três eixos de atuação - o eixo de garantia de renda, de acesso a serviços e de inclusão produtiva -, compreende processos de implementação de suas ações que ora se a- 
proximam mais da perspectiva top-down, ora da perspectiva bottom-up. Tais dinâmicas diferenciadas de implementação podem ser associadas igualmente ao assinalado por Berman (1978), sobre os dois processos distintos de implementação das políticas sociais, o processo de macro-implementação e de micro-implementação.

Enquanto que no nível da macroimplementação os aspectos institucionais mais amplos, como as estruturas e os programas das políticas e, mesmo as relações intergovernamentais possuem um papel maior; no nível da micro-implementação ocorre uma adaptação mútua entre a política local - a partir das diretrizes nacionais e as características organizacionais locais (BERMAN, 1978). Assim, o processo de implementação do BSM no Município de Curitiba é constituído pelos dois níveis apontados por Berman (1978), o referente à macro-implementação que está mais interligado às estruturas políticas mais amplas como o Sistema Único de Assistência Social (SUAS), o Sistema do Cadastro Único e do Programa Bolsa Família; e à microimplementação relacionado aos contextos locais e organizacionais de interação dos atores públicos entre si e destes com os beneficiários das políticas, como no caso dos ambientes organizacionais locais dos CRAS, dos Territórios Priorizados e os programas locais de inclusão produtiva.

Dessa forma, temos que o processo de implementação de políticas públicas é um fenômeno complexo e repleto de configurações institucionais, atores, interesses e beneficiários que interagem e se influenciam mutuamente impactando os resultados finais das políticas. A análise dos processos de implementação de políticas públicas torna-se, portanto, um campo de estudos ex- tremamente significativo e rico a ser explorado.

\section{REFERÊNCIAS}

BARRET, Susan M. Implementation studies: time for a revival? In: Personal reflections on 20 years of implementation studies, Public Administration, 82:2, 2004.

BERMAN, Paul. The study of macro and micro implementation of social policy. In: The Rand Paper Series. Santa Monica, California, USA, 1978.

BRASIL. Constituição Federal de 1988. Disponível em: <http://www.planalto.gov.br/ ccivil_03/constituicao/constituicaocompila do.htm> Acesso em: 28 mai. 2015.

. Política Nacional de Assistência Social (PNAS). Brasília: MDS, 2004.

- Tipificação Nacional de Serviços

Socioassistenciais. Brasília: MDS, 2009.

Decreto n.7492, de 2 de junho de 2011. Institui o Plano Brasil Sem Miséria. Disponível em: <http://www.planalto.gov. br/ccivil_03/_ato2011-2014/2011/Decreto/ D7492.htm > Acesso em: 03 mar. 2015. . Resolução $n^{\circ} 18$, de 24 de maio de 2012. Institui o Programa de Promoção do Acesso ao Mundo do Trabalho (Acessuas Trabalho). Brasília: MDS, 2012.

CURITIBA. Fundação de Ação Social. Instrução Normativa n.1, de 17 de agosto de 2015. Normatiza e orienta o desenvolvimento das ações previstas no Projeto Curitiba Sem Miséria. 2015a. . Instrução Normativa n.2, de 12 de novembro de 2015. Altera a Instrução Normativa FAS n.1/2015 que normatiza e orienta o desenvolvimento das ações previstas no Projeto Curitiba Sem Miséria. 2015b.

DRAIBE, Sônia Miriam. A construção institu- 
cional da política brasileira de combate à pobreza: perfis, processos e agenda. Cadernos de Pesquisa, n.34. Núcleo de Estudo de Políticas Públicas - NEPP - Universidade Estadual de Campinas - Unicamp, 1998b. DYE, Thomas R. Understanding public policy. 13a edição. USA: Pearson Education, 2011.

ENTREVISTADO 1 [mai. 2016] Profissional da Diretoria de Proteção Social Básica da Fundação de Ação Social de Curitiba. Entrevistador: Ingeborg Anni Rulf Cofré. Curitiba, 2016. 1 arquivo .mp3 (160 $\mathrm{min}$ ).

ENTREVISTADO 2 [mai. 2016] Profissional da Diretoria de Informações e gestão de Benefícios da Fundação de Ação Social de Curitiba. Entrevistador: Ingeborg Anni Rulf Cofré. Curitiba, 2016. 1 arquivo .mp3 (134 $\min )$.

ENTREVISTADO 3 [mai. 2016] Profissional da Superintendência de Planejamento da Fundação de Ação Social de Curitiba. Entrevistador: Ingeborg Anni Rulf Cofré. Curitiba, 2016. 1 arquivo .mp3 (133 $\mathrm{min}$ ).

ENTREVISTADO 4 e 5 [mai. 2016] Profissionais do CRAS e CREAS da Fundação de Ação Social de Curitiba. Entrevistador: Ingeborg Anni Rulf Cofré. Curitiba, 2016. 1 arquivo .mp3 (120 min).

ENTREVISTADO 6 [jun. 2016] Profissional do CRAS da Fundação de Ação Social de Curitiba. Entrevistador: Ingeborg Anni Rulf Cofré. Curitiba, 2016. 1 arquivo .mp3 (73 min).

FARIA, Carlos Aurélio Pimenta de. Implementação: ainda o 'elo perdido' da análise de políticas públicas no Brasil? Revista Debates, Porto Alegre, v.6, n.2, p. 13-36, maioago. 2012.

FONSECA, Ana; JACCOUD, Luciana; KARAM, Ricardo. Do Bolsa Família ao Brasil Sem Miséria: o desafio de universalizar a cidadania. In: FONSECA, Ana; FAGNANI, Eduardo
(Orgs). Políticas sociais, cidadania e desenvolvimento. Editora Perseu Abramo, Coleção Projetos para o Brasil, v.2, 2013.

FREY, K. Políticas Públicas: um debate conceitual e reflexões referentes à prática da análise de políticas públicas no Brasil. Planejamento e Políticas Públicas, n.21, jun de 2000.

GIL, A. C. Como elaborar projetos de pesquisa. 4a edição. São Paulo: Editora Atlas, 2007.

KRAFT, M. E.; FURLONG, S. R. Public Policy: politics, analysis and alternatives. 3a edição. USA: CQPress, 2010.

HILL, Michael; HUPE, Peter. Implementing Public Policy: governance in theory and in practice. Sage Publications, London, 2002. LIMA, Luciana Leite; D'ASCENZI, Luciano. Implementação de políticas públicas: perspectivas analíticas. Revista de Sociologia e Política, v.21, n.48, Curitiba, dez. 2013. LIPSKY, Michael. Street-level Bureaucracy: dilemmas of the individual in public services. New York: Russell Sage Foundation, The Thiertieth Anniversary, Expanded Edition, 2010.

LOTTA, Gabriela Spanghero. Implementação de Políticas Públicas: o impacto dos fatores relacionais e organizacionais sobre a atuação dos burocratas de nível de rua no Programa Saúde da Família. Tese de Doutorado. Universidade de São Paulo, Departamento de Ciência Política, São Paulo, 2010. MINAYO, Maria Cecília de Souza; SANCHES, Odécio. Quantitativo-Qualitativo: Oposição ou Complementaridade? Cadernos de Saúde Pública. Rio de Janeiro, 9 (3): 239-262, jul/sep, 1993.

SABATIER, Paul; MAZMANIAN, Daniel. The implementation of public policy: a framework of analysis. Policy Studies Journal. Volume 8, Issue 4, pages 538-560, January 
1980.

SOUZA, C. Políticas Públicas: uma revisão da literatura. Sociologias, Porto Alegre, ano 8 , n.16, jul/dez 2006.

Artigo recebido em 29 de setembro de 2017.

Aprovado em 29 de novembro de 2017. 